\title{
AN UNUSUAL CASE OF CONGENITAL PYLORIC STENOSIS
}

\author{
BY
}

\author{
ROBERT E. STEEN, M.D., F.R.C.P.I.
}

The following case of hypertrophic pyloric stenosis presents two very unusual features: first, the advanced age of the infant; and secondly, the intermittent character of the symptoms.

\section{Clinical report.}

V.K., female, aged 7 months, was admitted to the Hospital for Sick Children, Great Ormond Street, under the care of Dr. Robert Hutchison on the 28th November 1928, suffering from vomiting, constipation and wasting.

HistoRy. 7 weeks premature infant. Normal labour. Birth-weight 5lb. Progress appeared to be satisfact ory until $\mathbf{1 4}$ days old, when vomiting commenced. This was projectile in character, and frequently per nares. Constipation which had been present in a minor degree since birth now became severe. The stools were small and hard, and frequently none might be passed for 36 hours, and then only after the administration of an enema. The weight which had been increasing satisfactorily since birth now began to fall. Vomiting, constipation, and wasting continued with undiminished severity until the baby was $2 \frac{1}{2}$ months old, when these symptoms subsided suddenly and completely. The stools now resumed their normal colour and frequency, and the weight started to increase. This satisfactory state of affairs lasted six weeks, at the end of which time one large vomit occurred. A further fortnight passed with complete absence of symptoms, and then a second bout of severe vomiting commenced at $4 \frac{1}{2}$ months of age. Two days before the vomiting made its reappearance constipation again became severe and the parents stated that this gave them a warning that a relapse was about to occur. This second ' attack ' lasted one week, during which the child again lost weight. A further fortnight followed during which no vomiting occurred, constipation disappeared, and the child rapidly gained weight. $8 \mathrm{oz}$. were gained in the first week and $10 \mathrm{oz}$. in the second, the weight at the end of this period being $8 \frac{3}{4} \mathrm{lb}$. Everything suggested that the corner had been turned when at the end of the fortnight, i.e., at $5 \frac{1}{4}$ months, the third and final bout of vomiting began. Constipation again became severe and the weight fell steadily. This continued until admission 7 weeks later.

Child was never breast-fed. A large variety of foods were tried. At each change of food a temporary subsidence of vomiting occurred for one or two days.

One other child in family, female, aged 6, who had always been healthy. No blood relationship between parents.

On Admission. Very small wasted baby locking more like a 7 weeks than a 7 months infant. Weight 5 lb. 9 oz. Fontanelle sunken. Well-marked visible gastric peristalsis seen. The pyloric tumour was felt far out, nearly in the anterior axillary line. It felt very hard, about the size of a hazel nut. The heart, lungs, and nervous system were normal. Gastric lavage gave a very dirty brown result.

On account of the age of the child it was decided to adopt medical treatment. Thickened feeds were given two-hourly, with extra fluid a short time before feeds. Gastric lavage was performed daily.

Course. The temperature and pulse rate remained normal throughout. Vomiting continued in spite of treatment, though it diminished a little in severity, and on several days none occurred. No stool was passed during the first 36 hours in hospital. Subsequently the stools were noi mai in number, coiour and consistency, suggesting that a proportion of the food taken was 
passing the obstruction. The weight, after a temporary rise of a few ounces, became stationary and remained so until death. Gastric lavage almost always gave a large curdled thick result. On the 8th December the condition was not so good and a subcutaneous glucose saline was administered. On the 9th the child collapsed suddenly and passed a large light brown welldigested stool. A subcutaneous glucose saline was administered, but six hours later death occurred.

Post-mortem Examination. Performed 20 hours later. The stomach was very dilated and filled with gas. The pylorus was greatly hypertrophied for about $1 \frac{1}{2}$ inches (see Figures). It would not admit a probe, nor allow the passage of stomach contents. The rest of the gut was very small but normal in appearance except for slight injection of the mucosa.

Nothing abnormal was found in the rest of the body.

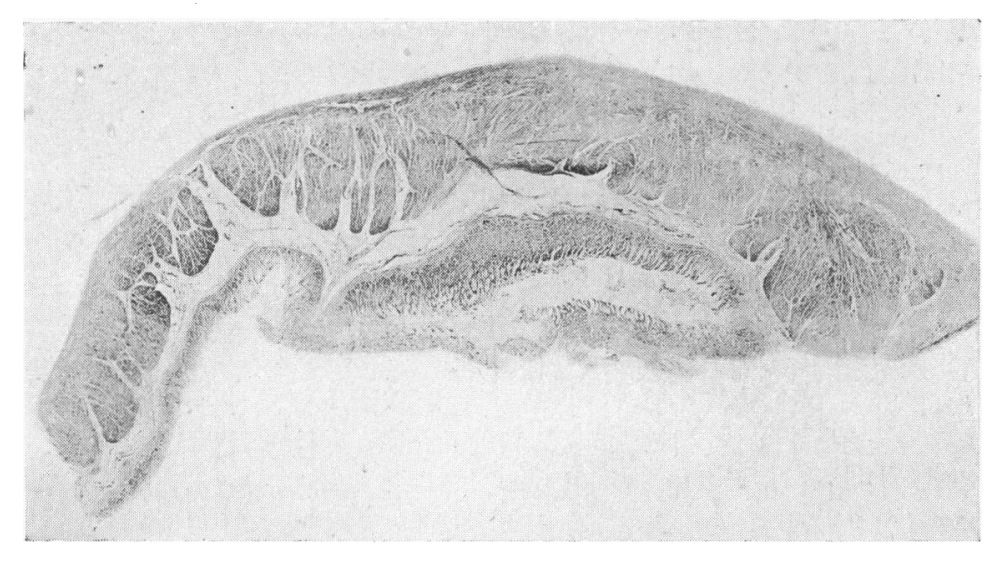

Section of the hypertrophied pylorus.

\section{Discussion.}

Congenital pyloric stenosis like many other diseases peculiar to childhood, displays a very clear-cut age-incidence. Most authorities regard it as a disease of infancy which, in the medically treated cases that survive, passes off spontaneously at the age of four or five months. "Untreated cases die from starvation in the first few months of life, generally in the third moith ${ }^{1}$.' It is suggested, however, by Chapin and Royster ${ }^{2}$ that when the stenosis is partial or slight, the attacks of vomiting may only occur at occasional intervals extending over a number of years. Unfortunately the authors do not give the evidence on which they base this statement. Oliver ${ }^{3}, \mathrm{Crohn}^{4}$, and others consider that the disease may in rare instances persist into adult life, but it would seem likely that such cases should be regarded as congenital malformations rather than true congenital hypertrophic stenosis of the pylorus, which is a very definite condition, remarkably self-limited. That the tumour may persist long after all symptoms of the disease have disappeared has been emphasized by Schlesinger ${ }^{5}$, who palpated it in a child of $3 \frac{1}{2}$ years old. Only one case at all comparable to the above would appear to have been recorded in the literature. This case, reported by Davison $^{6}$, was normal until eight months old, when all the cardinal symptoms of pyloric stenosis developed, projectile vomiting, constipation, visible gastric peristalsis, and a palpable tumour. The extraordinarily 
late onset of symptoms in this infant would suggest that the ætiology was not similar to that of ordinary congenital pyloric stenosis. Out of 463 cases of pyloric stenosis admitted to the Hospital for Sick Children, Great Ormond Street, during the ten years 1919-1929, only one other case presented symptoms of the disease at an age above five months. This patient was admitted under the

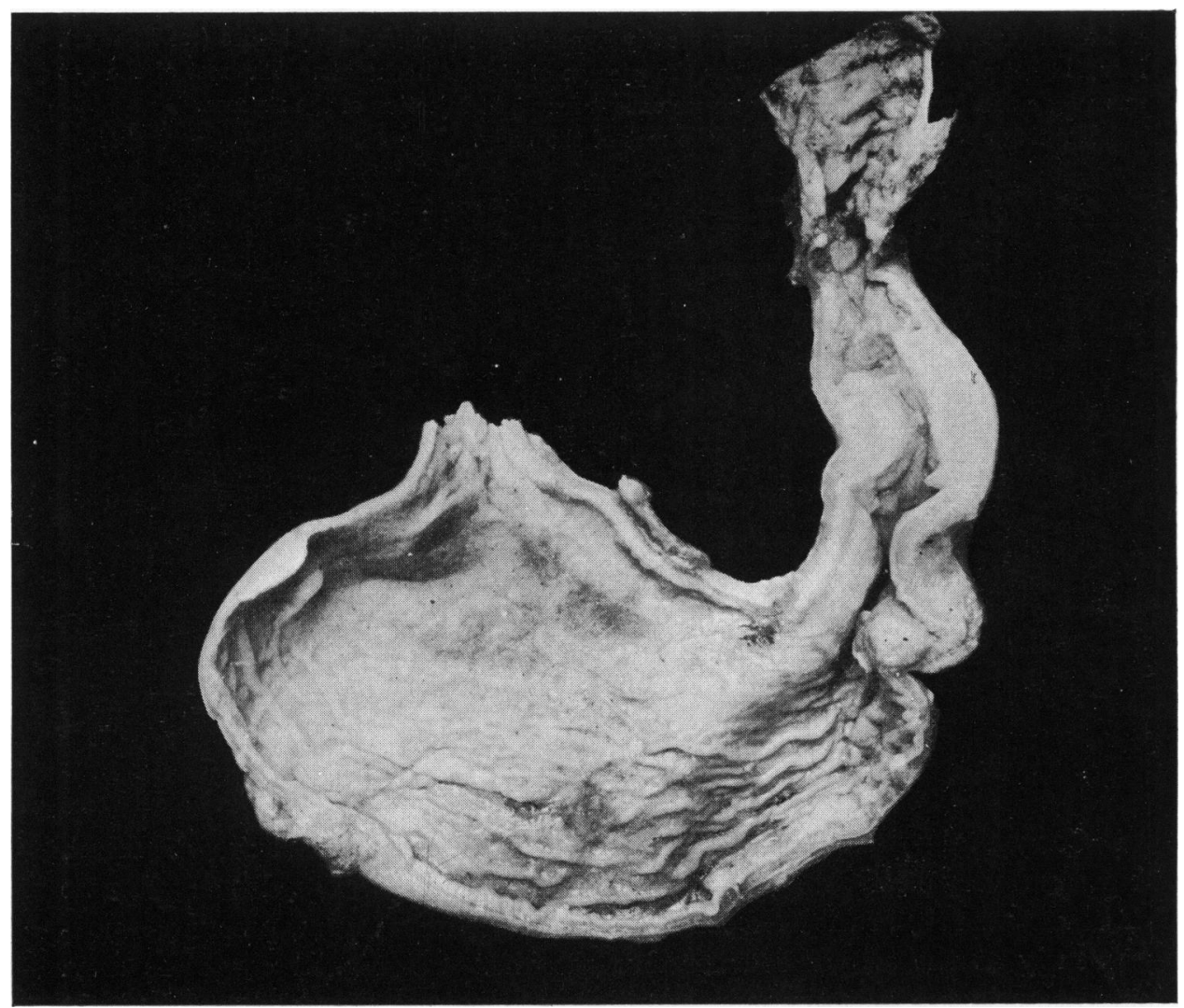

Photograph shewing the dilated stomach with the hypertrophied pylorus.

care of Dr. Still in 1921, at the age of six months and died three weeks later. The present case may therefore be considered as remarkable in that symptoms of obstruction were present as late as $7 \frac{1}{2}$ months, the age at which death supervened. It is a question of some interest whether the seven weeks prematurity can have been a factor in determining the great prolongation. It is interesting to note that Dr. Still's case was a four weeks premature infant. It is probable that the date of onset of symptoms was in each case precipitated by the abnormally early functioning of the alimentary tract as a result of the premature birth. Measuring the age from the date of conception would then in part explain the peculiar senility of the two cases. This again might throw some light on the mechanism of the spontaneous recovery which occurs in those cases of pyloric stenosis which survive, adding support to the theory that the natural cure is effected by the growth of the pylorus. It is reasonable to expect 
that this would be somewhat delayed in premature infants, few of which, however, would be likely to survive the severe degree of inanition which accompanies prolonged pyloric obstruction.

A fact of perhaps even greater interest was the intermittent character of the symptoms. Dr. Still ${ }^{7}$ has emphasized this feature as additional evidence that the obstruction is at least in part due to spasm of the pylorus. He mentions cases in his experience in which infants suffering from pyloric stenosis had intervals of from two, three, or even as long as five days, when vomiting temporarily ceased entirely and food passed through the pylorus normally. Such instances must be clearly distinguished from those other not infrequent cases where vomiting ceases for twenty-four or forty-eight hours in some unexplained way as a result of a change in the diet; or where as the stomach dilates and the infant becomes weaker, vomiting diminishes in frequency and intensity, and may be quite absent for as many as twelve days in succession ${ }^{8}$. In such cases of course no improvement in the condition of the child occurs. No case would appear to have been recorded which will compare with the one reported here, in which the remissions were measured not in days, but in weeks and months.

Further proof of the part which spasm plays in causing the obstruction is furnished by the character of the stools in the present case during the two weeks preceding death. These demonstrated clearly that a considerable proportion of the food was beginning to pass the pylorus, the latter presumably relaxing as part of the terminal asthenia. It is likely therefore, that the appearance of more normal stools without improvement in the general condition of the child is to be regarded as of bad prognostic significance.

Lastly, this case raises the question of medical versus surgical treatment in older cases of congenital pyloric stenosis. Many advise against operating on infants of three or four months old, holding that such patients are approaching the point of spontaneous recovery. The case reported, though exceptional, shows that this reasoning may be fallacious, especially perhaps in the case of premature infants.

I am indebted to Dr. Robert Hutchison for permission to publish this case.

\section{REFERENCES.}

1. Garrod, A. E., Batten, F., Thursfield, J. H., and Paterson, D., Diseases of Children, Lond., 2nd Ed., 1929.

2. Chapin \& Royster, Dis. of Infants and Children, 1929.

3. Oliver, J. C., Ann. Surg., Philad.: 1922, LXXVI, 444.

4. Crohn, Burril B., J. Am. Med. Ass., Chicago, 1928, XC, 197.

5. Schlesinger, B. E., Proc. Roy. Soc. Med., Lond., 1925, XVIII (Sect. Dis. Child.), 40.

6. Davison, Wilburt C., Bull. John Hopkins Hosp., Baltimore, 1925, XXXVII, 75.

7. Still, G. F., Brit. Med. J., Lond., 1923, i, 579.

8. Steen, R. E., Irish Med. J., 1929, 6.S., XL, 163. 